\title{
Late-onset X-linked adrenal hypoplasia (DAX-1, NROB1): two new adult-onset cases from a single center
}

\author{
Nikolaos Kyriakakis ${ }^{1,2} \cdot$ Tolulope Shonibare $^{1} \cdot$ Julie Kyaw-Tun $^{1} \cdot$ Julie Lynch $^{1}$ • \\ Carlos F. Lagos $^{3,4} \cdot$ John C. Achermann ${ }^{5}$ Robert D. Murray ${ }^{1,2}$
}

Published online: 24 July 2017

(C) The Author(s) 2017. This article is an open access publication

\begin{abstract}
Purpose DAX-1 (NROB1) is an orphan nuclear receptor, which plays a critical role in development and regulation of the adrenal gland and hypothalamo-pituitary-gonadal axis. Mutations in NROBI lead to adrenal hypoplasia congenita (AHC), hypogonadotropic hypogonadism $(\mathrm{HH})$ and azoospermia in men. Presentation is typically with adrenal insufficiency (AI) during infancy or childhood. To date only eight cases/kindreds are reported to have presented in adulthood.

Methods We describe two new cases of men with DAX-1 mutations who presented in adulthood and who were diagnosed at a large University Hospital.

Results Case 1 presented with AI at 19 years. At 38 years he was diagnosed with HH. Detailed history revealed a brother diagnosed with AI at a similar age. Sequencing of the DAX-1 (NROB1) gene revealed a heterozygous c.775T $>\mathrm{C}$ substitution in exon 1 , which changes codon 259 from serine to proline (p.Ser259Pro). Case 2 was diagnosed with AI at 30 years. Aged 37 years he presented
\end{abstract}

Robert D. Murray

robertmurray@nhs.net

1 Department of Endocrinology, Leeds Centre for Diabetes \& Endocrinology, St James's University Hospital, Leeds Teaching Hospitals NHS Trust, Beckett Street, Leeds LS9 7TF, UK

2 Leeds Institute of Cardiovascular and Metabolic Medicine, University of Leeds, Leeds, UK

3 Department of Endocrinology, School of Medicine, Pontificia Universidad Católica de Chile, Santiago, Chile

4 Facultad de Ciencia, Universidad San Sebastián, Campus Los Leones, Lota 2465 Providencia, 7510157 Santiago, Chile

5 Genetics \& Genomic Medicine, UCL Great Ormond Street Institute of Child Health, London, UK with $\mathrm{HH}$ and azoospermia. He was treated with gonadotropin therapy but remained azoospermic. Testicular biopsy showed maturational arrest and hypospermatogenesis. Analysis of the NROBI gene showed a heterozygous c. $836 \mathrm{C}>\mathrm{T}$ substitution in exon 1 , resulting in a change of codon 279 from proline to leucine (p.Pro279Leu). This change alters the structure of the repression helix domain of DAX-1 and affects protein complex interactions with NR5A family members.

Conclusions We describe two missense mutations within the putative carboxyl-terminal ligand binding domain of DAX-1, presenting with AHC and $\mathrm{HH}$ in adulthood, from a single center. DAX-1 mutations may be more frequent in adults than previously recognized. We recommend testing for DAX-1 mutations in all adults with primary AI and $\mathrm{HH}$ or impaired fertility where the etiology is unclear.

Keywords DAX-1 - Adrenal hypoplasia congenita . Adrenal insufficiency · Hypogonadotropic hypogonadism . Repression helix domain $\cdot$ Nuclear receptors

$\begin{array}{ll}\text { Abbreviations } \\ \text { ACTH } & \text { Adrenocorticotropin hormone } \\ \text { AHC } & \text { Adrenal hypoplasia congenita } \\ \text { AI } & \text { Adrenal insufficiency } \\ \text { CF } & \begin{array}{l}\text { Cystic fibrosis } \\ \text { Dosage sensitive sex reversal, adrenal hypo- } \\ \text { plasia, critical region on the X chromosome, } \\ \text { DAX-1 }\end{array} \\ & \text { gene 1 } \\ \text { FSH } & \text { Follicle-stimulating hormone } \\ \text { hCG } & \text { Human chorionic gonadotropin } \\ \text { HH } & \text { Hypogonadotrophic hypogonadism } \\ \text { hMG } & \text { Human menopausal gonadotropin } \\ \text { GnRH } & \text { Gonadotropin releasing hormone } \\ \text { IU } & \text { International units }\end{array}$




$\begin{array}{ll}\text { IVF } & \text { In-vitro fertilisation } \\ \text { kDA } & \text { Kilo Dalton } \\ \text { L } & \text { Litre } \\ \text { LBD } & \text { Ligand binding domain } \\ \text { LH } & \text { Luteinizing hormone } \\ \text { LRH } & \text { Liver receptor homolog-1 } \\ \text { mmol } & \text { Millimole } \\ \text { nmol } & \text { Nanomole } \\ \text { NR0B1 } & \text { Nuclear receptor subfamily 0, group B, } \\ & \text { member 1 } \\ \text { NR5A1 } & \begin{array}{l}\text { Nuclear receptor subfamily } 5 \text {, group A, } \\ \text { member 1 }\end{array} \\ \text { NR5A2 } & \text { Nuclear receptor subfamily 5, group A, } \\ & \text { member 2 } \\ \text { pmol } & \text { Picomole } \\ \text { RH } & \text { Repression helix } \\ \text { SDS } & \text { Standard deviation scores } \\ \text { SF-1 } & \text { Steroidogenic factor-1 } \\ \text { SHBG } & \text { Steroid hormone binding globulin } \\ \text { TESE-ICSI } & \text { Testicular sperm extraction for intracytoplas- } \\ & \text { mic sperm injection }\end{array}$

\section{Introduction}

Primary adrenal insufficiency (AI) is a potentially lifethreatening condition that results from a number of differing etiologies including autoimmune, genetic, and developmental disorders. The etiology is important for establishing potential associated comorbidities, inheritance, and optimal management. DAX-1 (dosage sensitive sex reversal, adrenal hypoplasia, critical region on the $\mathrm{X}$ chromosome, gene 1) is an orphan nuclear receptor encoded by the $N R O B 1$ gene. DAX-1 has a characteristic carboxyl-terminal ligand-binding domain (LBD) and an atypical DNA binding domain. The gene is located on the short arm of the $\mathrm{X}$ chromosome, in the $\mathrm{Xp} 21$ region, and plays a critical role in the embryological development of multiple endocrine tissues. It is expressed in the hypothalamus, pituitary gland, adrenals and gonads. After completion of tissue development DAX-1 continues to play a role in the regulation of hormone production.

Clinically, mutations in DAX-1 result in the X-linked form of primary adrenal hypoplasia congenita (AHC), hypogonadotrophic hypogonadism $(\mathrm{HH})$ and azoospermia in men $[1,2]$. Classically, males present in infancy or early childhood, with primary adrenal failure or isolated mineralocorticoid deficiency, with $\mathrm{HH}$ becoming apparent in adolescence by absent or arrested pubertal development [3]. Females are carriers and therefore generally unaffected. A spectrum of clinical presentations have been described, including delayed onset of AI and partial $\mathrm{HH}$ or even transient early puberty $[4,5]$. In contrast, the description of
DAX-1 (NROB1) gene mutations presenting with onset of $\mathrm{AI}$ and $\mathrm{HH}$ in adulthood are rare.

We present two men with adult-onset $\mathrm{AI}$ and $\mathrm{HH}$, who were found to have DAX-1 mutations, in addition to reviewing the previously described cases/kindreds of DAX-1 mutations presenting during adulthood.

\section{Case 1}

A 42-year-old man with known cystic fibrosis (CF) and secondary diabetes was referred to Endocrinology for management of his Addison's disease and androgen replacement. He was diagnosed with $\mathrm{CF}$ aged 4 years. As a consequence of $\mathrm{CF}$ he suffered mild abrogation of growth, with a final height of -2.5 SDS. His corresponding weight was -1.4 SDS, and pubertal development was assessed to be Tanner stage 5 at age 16. At age 18 years he was diagnosed with CF-related diabetes mellitus requiring insulin. During admission with a respiratory exacerbation of his $\mathrm{CF}$ at age 19 years he was noted to be pigmented, with serum sodium $124 \mathrm{mmol} / \mathrm{L}$ and potassium $5.1 \mathrm{mmol} / \mathrm{L}$. Further tests confirmed cortisol insufficiency [9am cortisol $<50 \mathrm{nmol} / \mathrm{L}$ $(<1.8 \mu \mathrm{g} / \mathrm{dL})]$ in association with unrecordable aldosterone $[<55 \mathrm{pmol} / \mathrm{L}(<1.5 \mathrm{ng} / \mathrm{dL})]$. Plasma renin activity is not available from the time of diagnosis. The patient was diagnosed with Addison's disease and commenced on hydrocortisone and fludrocortisone replacement. At the time of the AI diagnosis the patient was on a regular Budesonide inhaler. However he was not on any oral medications (i.e. oral steroids or imidazoles), which could have caused iatrogenic adrenal insufficiency.

At 35 years of age he underwent lung transplantation for end-stage pulmonary disease, necessitating long-term corticosteroid and immunosuppressive therapy with tacrolimus and mycophenolate mofetil. At age 38 years he presented with symptoms of low libido, was found to have HH [LH 1.6 IU/L, FSH $10.2 \mathrm{IU} / \mathrm{L}$, testosterone $3.3 \mathrm{nmol} / \mathrm{L}$ (95 ng/dL), SHBG $48 \mathrm{nmol} / \mathrm{L}$, estradiol 54pmol/L (14.7 pg/ $\mathrm{mL}$ )], and was commenced on testosterone replacement. At the time of diagnosis of $\mathrm{HH}$ the patient was on hydrocortisone, as well as tacrolimus and mycophenolate mofetil. He was then lost to endocrine follow-up, however, on representation aged 42 years, a detailed history revealed he had a brother diagnosed with Addison's disease at a similar age. Investigations of additional pituitary axes were within normal limits [TSH $1.29 \mathrm{miu} / \mathrm{L}$ (reference range 0.2-4.0), free T4 $17.9 \mathrm{pmol} / \mathrm{L}$ (reference range 10.0-20.0), prolactin $278 \mathrm{miu} / \mathrm{L}$ (normal level $<600$ )], and a pituitary MRI was unremarkable. Neither the patient nor his brother have fathered children. Given the presence of Addison's disease with $\mathrm{HH}$, potential infertility, and family history, the patient was tested for mutation in the DAX-1 (NROB1) 
gene. DNA analysis revealed a heterozygous c.775T $>$ C (p.Ser259Pro) substitution within exon 1 of the DAX gene, which changes codon 259 from serine to proline in the putative LBD (Fig. 1). The results of in silico analysis suggested causality. p.Ser259 is a highly conserved amino acid in the ligand binding domain of the nuclear hormone receptor core of DAX1. SIFT (http://www.blocks.fhcrc.org/ sift) predicts that p.Ser259Pro will affect protein function. Polyphen (http://www.genetics.bwh.harvard.edu) predicts p.Ser259Pro to be probably damaging. Russell analysis (http://www.russell.embl.de/ass) predicts the amino acid substitution from serine to proline to be disfavoured. Splicing (Alamut) c.775T $>\mathrm{C}$ is predicted that the variant does not affect the splicing of DAX1. The patient has declined genetic counseling, as he has not had any family plans so far.

\section{Case 2}

A 30-year-old man presented with hyponatremia and hyperpigmentation. The presence of AI was confirmed with a short synacthen test (stimulation with 250 micrograms of synacthen), which revealed a baseline cortisol of $94 \mathrm{nmol} / \mathrm{L}$ $(3.4 \mu \mathrm{g} / \mathrm{dL})$ and a peak cortisol of $112 \mathrm{nmol} / \mathrm{L}(4 \mu \mathrm{g} / \mathrm{dL})$. Serum aldosterone was $<55 \mathrm{pmol} / \mathrm{L}(<1.5 \mathrm{ng} / \mathrm{dL})$; however plasma renin activity is not available from the time of diagnosis. Adrenal antibodies were negative. He was diagnosed with Addison's disease and commenced on hydrocortisone and fludrocortisone. At that time it was commented that his secondary sexual characteristics were normal, however, his testes were small. Gonadotropins showed LH 4.0 IU/L and FSH 10.0 IU/L, however a testosterone from that time is not available.

Seven years later he presented to the Urology department with ejaculatory failure and subfertility. On examination his secondary sexual characteristics were documented to be consistent with androgen deficiency. He had a small left testis and an impalpable right testis due to a hydrocele. Semen analysis and post-ejaculatory urine showed azoospermia. His initial pituitary hormone profile revealed $\mathrm{LH}<0.5 \mathrm{IU} / \mathrm{L}$, FSH $5.5 \mathrm{IU} / \mathrm{L}$ and testosterone $<0.9 \mathrm{nmol} / \mathrm{L}$ $(26 \mathrm{ng} / \mathrm{dL})$. His remaining pituitary hormone profile was unremarkable [TSH $0.84 \mathrm{miu} / \mathrm{L}$ (reference range 0.2-4.0), free T4 $13.8 \mathrm{pmol} / \mathrm{L}$ (reference range 10-20), random $\mathrm{GH}<0.1 \mathrm{mcg} / \mathrm{L}$, IGF-1 $36.9 \mathrm{nmol} / \mathrm{L}$ (reference range 10.1-28.4), prolactin $77 \mathrm{miu} / \mathrm{L}$ (normal level<600)], and pituitary imaging revealed no abnormalities. GnRH stimulatory test showed peak LH and FSH of 1.0 and $8.4 \mathrm{IU} / \mathrm{L}$ respectively. He was commenced on hCG and hMG injections which normalised his testosterone level $[22.1 \mathrm{nmol} / \mathrm{L}$ (636 ng/dL)], sexual function, and secondary sexual characteristics, however, he remained azoospermic. He was referred to the Assisted Conception Unit and testicular sperm extraction (TESE) was attempted, but failed. Histological examination of his testis showed maturational

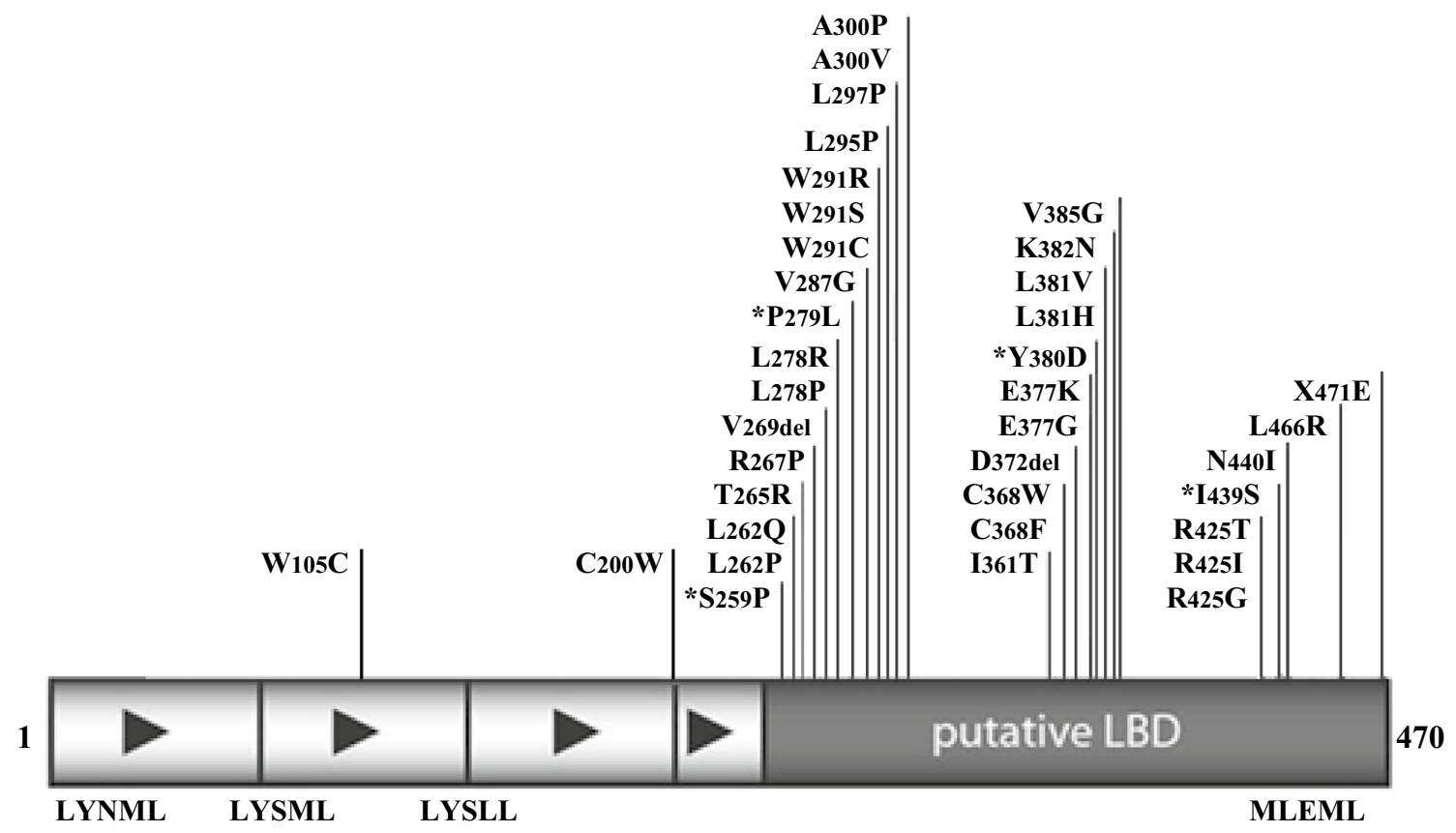

Fig. 1 Schematic diagram of the DAX-1 protein showing reported missense mutations [6]. Asterisk represent mutations associated with adult presentation of Adrenal Hypoplasia Congenita and Hypogon- adotropic Hypogonadism (Modified with permission from Lin et al. Copyright ( 2006 by The Endocrine Society) 
arrest and hypospermatogenesis (Fig. 2). He was commenced on androgen replacement and continued his management under the Endocrine team. The association of AI and $\mathrm{HH}$ with poor response to fertility treatment prompted testing of the DAX-1 (NROBI) gene. The test was performed by direct sequencing and revealed a hemizygous c836C $>\mathrm{T}$ substitution in exon 1 . This missense mutation occurs within a 'hot spot' in the putative ligand binding domain which changes codon 279 from proline to leucine (p.Pro279Leu) (Fig. 1). The mutation has not previously been reported on the Human Genome Mutation Database and is not listed as a single nucleotide polymorphism (SNP) using the SNP-checker software. Investigation of
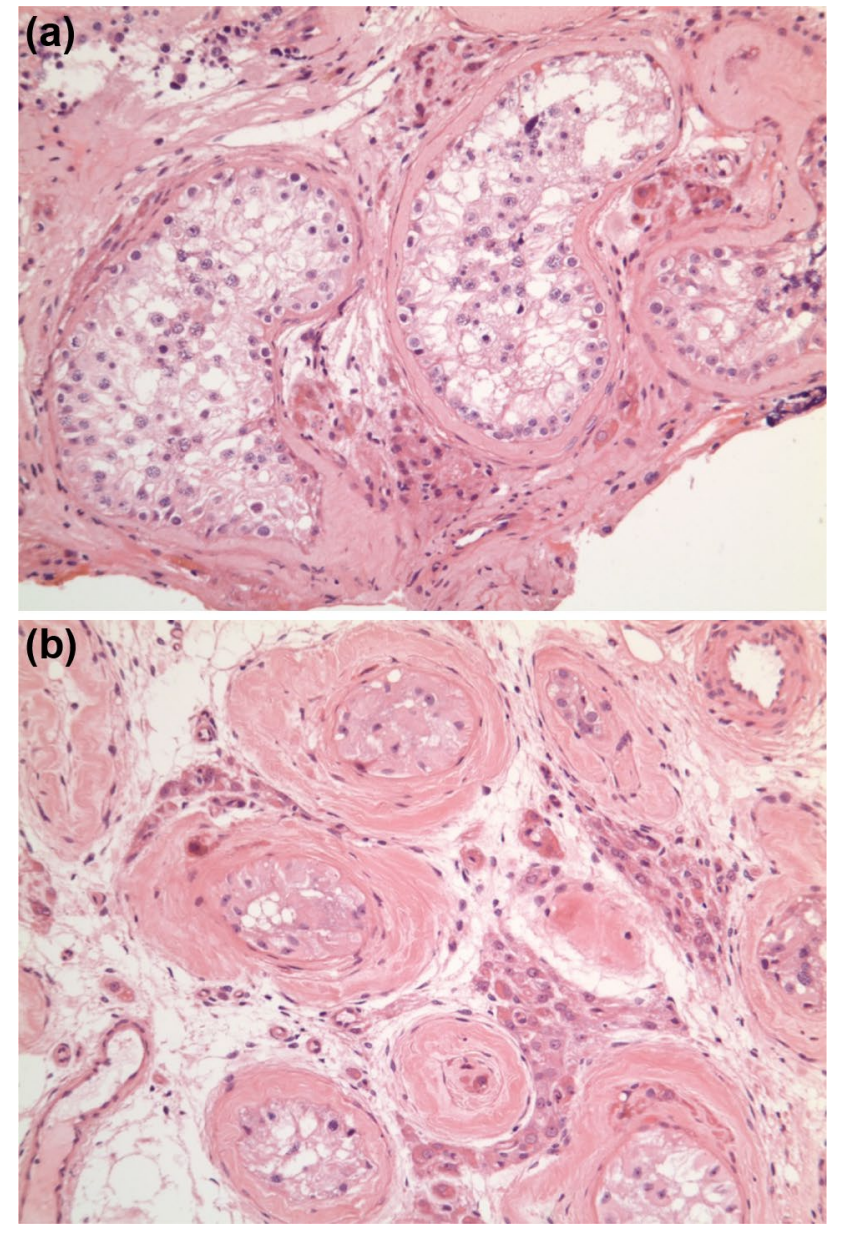

Fig. 2 Histology obtained from testicular biopsy of patient with hemizygous c836C $>\mathrm{T}$ substitution in exon 1 of the DAX1 (NR0B1) gene. This missense mutation occurs within a 'hot spot' in the putative ligand binding domain which changes codon 279 from proline to leucine (p.Pro279Leu); a Demonstrates maturational arrest of spermatogenesis. The tubules contain germ cells but in low numbers. There is maturation up to primary spermatids but absent spermatazoa; b Demonstrates hyalinised and atrophic tubules (Sertoli cells only). Leydig cells are observed between the tubules. They are more easily seen compared to normal testis because of the general paucity of tubules (pseudohyperplasia) the possible pathogenicity of this variation using Alamut software, as well as modelling, revealed that the sequence change occurs in both a highly conserved nucleotide and highly conserved amino acid that likely interacts directly with NR5A1/SF-1 (Fig. 3). The patient has not required genetic counseling with regards to his DAX-1 mutation, as previous investigations have shown infertility. He and his partner have now become parents to a healthy child following assisted conception via donor insemination.

Table 1 summarizes the endocrine investigations which led to the diagnosis of primary $\mathrm{AI}$ and $\mathrm{HH}$ in both our cases.

\section{Discussion}

We describe two unrelated men who demonstrate clinical presentation of X-linked adrenal hypoplasia during adulthood. In keeping with the majority of previous descriptions, both cases presented with AI prior to HH. In our patients AI was diagnosed at the age of 19 and 30 years, with hypogonadism diagnosed at 38 and 37 years respectively. Both DAX-1 mutations detected within our cases lie within the putative ligand binding domain (LBD).

The NROB1 gene encodes a $51 \mathrm{kDa}$ protein which is part of the orphan nuclear receptor superfamily. The amino terminus containing three LXXLL-like motifs is implicated in protein-protein interactions, and the carboxyl terminus is a classic LBD. DAX-1 regulates development and function of the adrenal cortex and hypothalamo-pituitary-gonadal axis $[1,2]$, primarily by repression of gene expression. In part its actions are mediated by repression of another nuclear receptor, steroidogenic factor-1 (SF-1, NR5A1) [10]. Mutations in DAX-1/NROBI classically present in males during infancy or childhood with primary adrenal failure or less commonly isolated mineralocorticoid deficiency, with hypogonadism becoming apparent as failure to enter or progress through puberty [3,11]. A further feature of mutations in DAX-1 is a primary defect in spermatogenesis [12], characterized typically by failure to respond to exogenous gonadotropins [11, 13]. A single birth has been reported after finding rare spermatozoa in a man with $\mathrm{HH}$ resulting from a DAX-1 mutation after TESE-ICSI [14]. In addition to the more classic presentation, isolated $\mathrm{HH}$ in a female homozygous for mutations in NROBI [15]; extreme pubertal delay in heterozygous female carriers [13]; 46,XY gonadal dysgenesis resulting from duplication of Xp21.2 [16]; and AHC as part of skewed X inactivation [17] have been described in females. More than 80 mutations in DAX-1 have been described, the majority of which are nonsense or frameshift mutations resulting in a truncated protein $[5,18]$. Deletion of as few as the last 


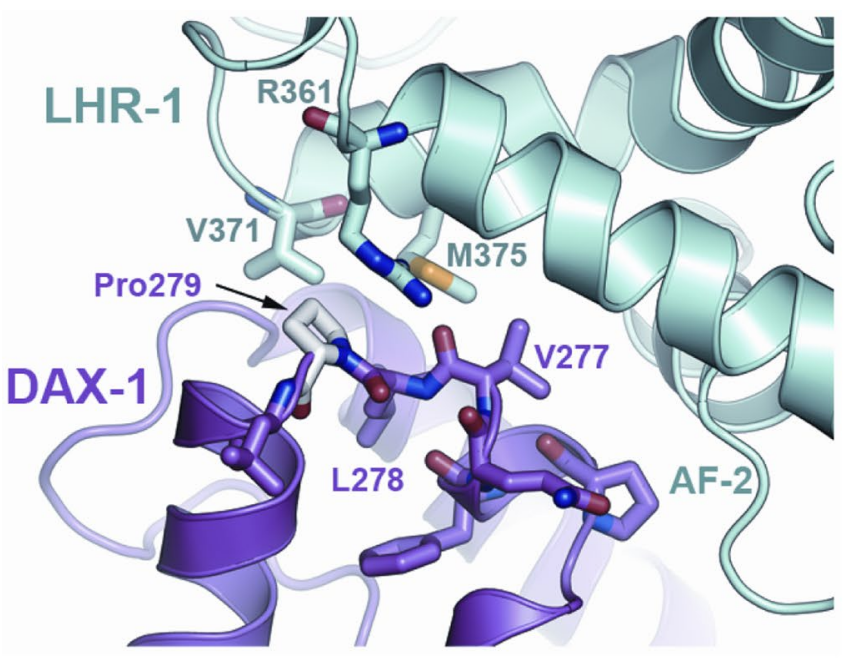

Fig. 3 Model of the effect of the p.Pro279Leu mutation on the DAX1:LRH-1 complex. The proline at 279 (shown in white, left panel) flanks the core repression helix domain of DAX-1 (magenta). The change to leucine (shown in white, right panel) likely increases the flexibility of the loop and produces a small displacement of an arginine side chain in LRH-1 (cyan). The comparative modelling of the human DAX-1: LHR-1 (Uniprot codes P51483 and O00482) complex was performed using the MODELLER program [7], as implemented in the Build Homology Model module of Discovery Studio v2.1 software (Accelrys Inc., San Diego, USA). The crystal structure

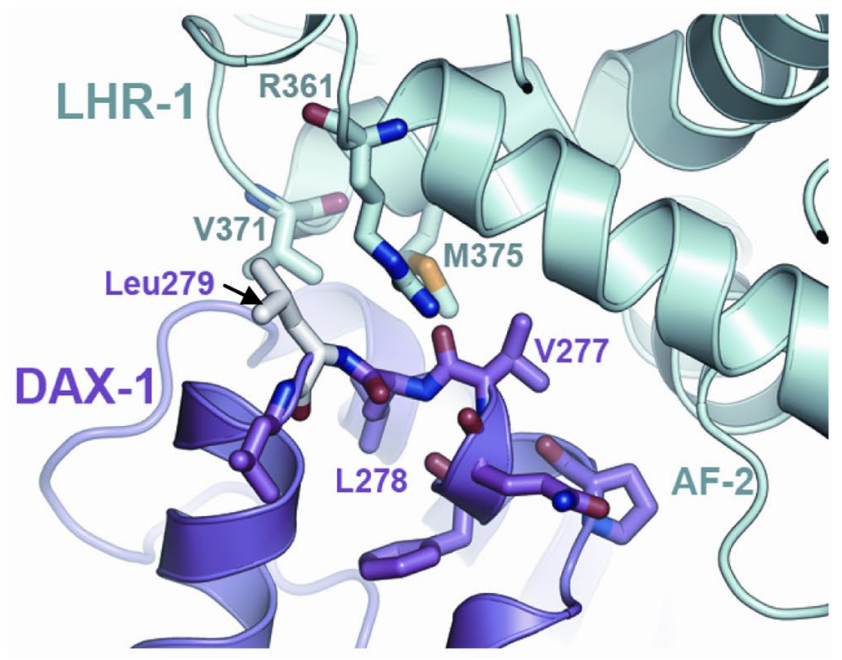

of murine DAX-1:LHR-1 complex (PDBid 3F5C) solved at $3.0 \AA$ resolution was used as template [8]. The protein complexes for the wild type and DAX-1 p.Pro279Leu mutant were modelled as (DAX$1)_{2}$ :LHR-1 trimers, following the crystal structure oligomerization state. The resultant models were energy minimized using the conjugate gradient algorithm with the CHARMM22 force field until a RMS gradient of $0.001 \mathrm{kcal} / \mathrm{mol} \AA$ was reached; a dielectric constant of 80 and a distance-dependent dielectric model was used during minimization [9]
Table 1 Summary of the endocrine investigations performed in the two adult cases of DAX-1 (NROB1) gene mutations ( $n / a$ not available)

\begin{tabular}{llll}
\hline Test & Case 1 & Case 2 & Reference range \\
\hline 9am Cortisol (nmol/L) & $<50$ & Not performed & $150-600$ \\
Short Synachten Test (nmol/L) & Not performed & 94 (cortisol at 0 min) & $\begin{array}{c}\text { Corti- } \\
\text { sol }>500 \mathrm{nmol} / \mathrm{L} \\
\text { at 30 min }\end{array}$ \\
& & 112 (cortisol at 30 min) & $150-850$ \\
Aldosterone (pmol/L) & $<55$ & $<55$ & $0.5-3.5$ \\
Plasma renin activity (nmol/L/h) & $\mathrm{n} / \mathrm{a}$ & $\mathrm{n} / \mathrm{a}$ & $8.0-30.0$ \\
Testosterone (nmol/L) & 3.3 & $<0.9$ & $1.0-9.0$ \\
LH (IU/L) & 1.6 & $<0.5$ & $1.0-9.0$ \\
FSH (IU/L) & 10.2 & 5.5 & $13-71$ \\
SHBG (nmol/L) & 48 & $\mathrm{n} / \mathrm{a}$ & $<600$ \\
Prolactin (miu/L) & 77 & $0.2-4.0$ \\
TSH (miu/L) & 278 & 0.84 & $10-20$ \\
Free T4 (pmol/L) & 1.2 & 13.8 & - \\
GH (mcg/L) & 17.9 & $<0.1$ & $10.1-28.4$ \\
IGF-1 (nmol/L) & $\mathrm{n} / \mathrm{a}$ & 36.9 &
\end{tabular}

nine amino acids of the DAX-1 protein, constituting the putative activation function-2 domain, is associated with a severe clinical phenotype [19]. Less common are missense mutations which predominantly cluster within the putative carboxyl LBD [11, 20]. Considerable variability in presentation, even within affected family members, is described, relating primarily to timing of presentation of adrenal insufficiency [1, 21, 22], although there is a suggestion that younger brothers are diagnosed earlier, likely representing increased awareness [23].

To date we are aware of only eight other reports of DAX-1 mutations in cases/kindreds presenting in adulthood (Table 2) [22, 24-29]. Three of these are associated with amino-terminal nonsense changes in DAX-1, and five are associated with carboxyl-terminal missense mutations. Table 2 summarizes the clinical cases of adult-onset adrenal 


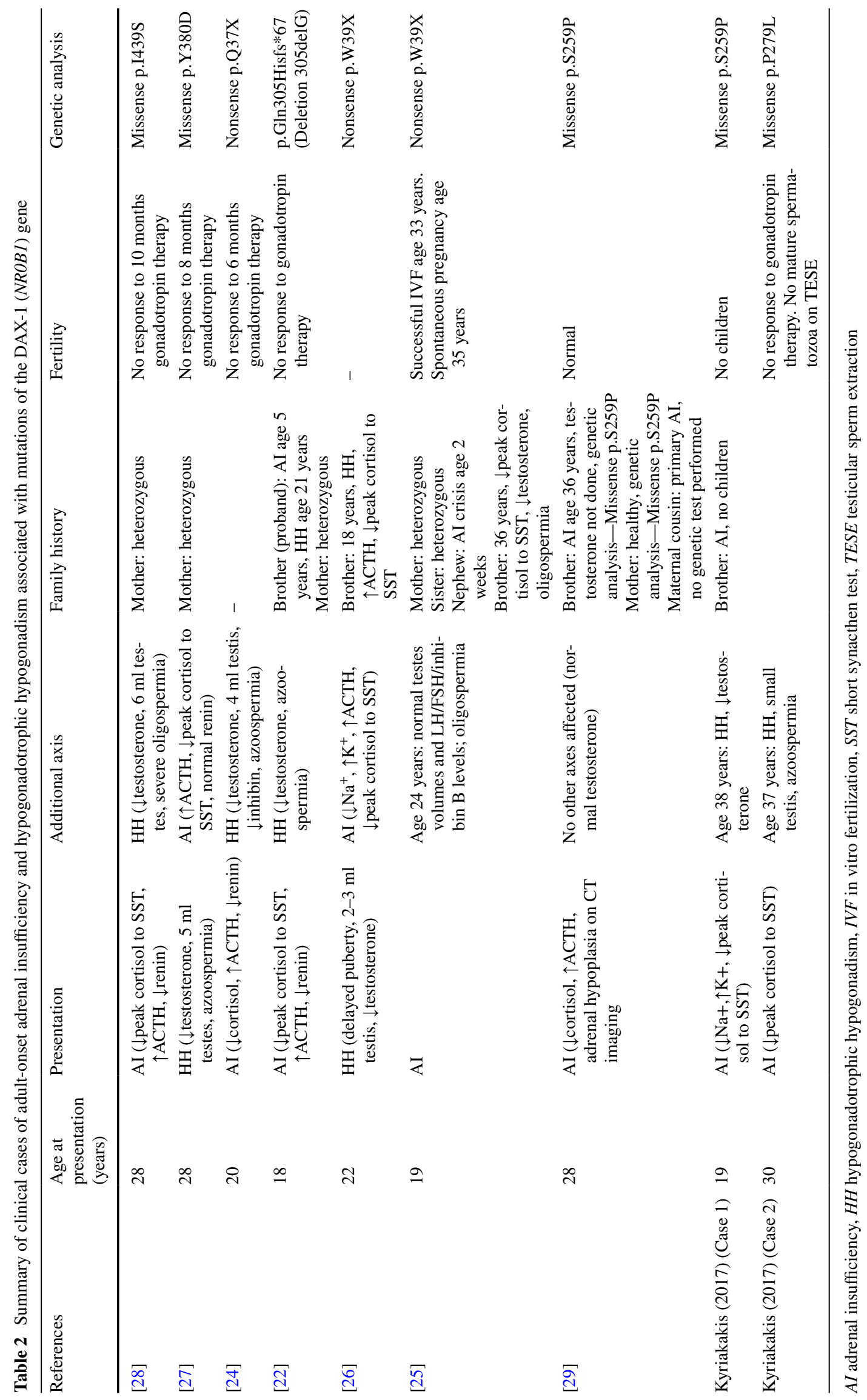


insufficiency and hypogonadotrophic hypogonadism associated with mutations of the DAX1 (NR0B1) gene. Most of these patients presented with $\mathrm{AI}$; however in two cases $\mathrm{HH}$ was the initial presentation, with the diagnosis of AI occurring at a later stage following further endocrine investigations. A recent case report described the same p.Ser259Pro mutation, as we found, in two Korean brothers who presented with primary AI at the age of 28 and 36 years respectively without evidence of hypogonadism [29]. The mutant protein showed reduced expression and impaired DAX-1 function in an in vitro assay. Clearly, these men will need follow-up, as hypogonadism may occur several years later, based on our experience.

To date, the described mutations within DAX-1 kindreds which have at least one case presenting in adult life include p.Q37X, p.W39X in two kindreds, p.S259P in three patients, p.P279L, p.Gln305Hisfs*67 (c.915delG), p.Y380D, and p.I439S (Table 2). The first two of these mutations result in a functional DAX-1 protein from an in-frame translational site downstream to the premature stop codon [24-26]. The next four of the described mutations are missense mutations widely distributed throughout the carboxyl LBD, but that may form important structural components of the protein structure or affect subcellular localisation [27, 28]. The final described mutation was a frameshift within the LBD [22].

Our patients add to previous reports of late-onset $\mathrm{X}$-linked AHC presenting in adulthood, and expand the list of DAX-1 mutations that can present in this way. The p.Pro279Leu mutation is a novel missense mutation within the LBD, which to our knowledge has not been previously reported in the literature. Based on the crystal structure of DAX-1 bound to NR5A2/LRH-1, this codon is one of two highly conserved proline residues flanking a unique repression helix (RH) domain that interacts directly with NR5A2 (Fig. 3) [8]. The core of this RH domain is a variant "LXXLL" motif containing exposed hydrophobic residues (Human sequence: 273_279PCFQVLP; Mouse sequence: 275_281PCFQILP). This region of DAX-1 blocks the interaction of co-activator with NR5A2, resulting in transcriptional repression. The proline at 279 flanks the core region. The change to leucine increases the flexibility of the loop and produces a small displacement of an arginine side chain in LRH-1. This change causes partial disruption of the protein-protein interaction and a delayed-onset phenotype. Of note, p.Leu278Arg and p.Leu278Pro variants affecting the core leucine have been reported in patients with classic early-onset X-linked adrenal hypoplasia.

The p.Ser259Pro mutation, which is the most aminoterminal mutation described in the putative LBD to date (Fig. 1), has also been recently reported in two Korean brothers with late-onset primary AI and no evidence of hypogonadism [29]. The authors demonstrated that the mutation caused a loss of the NR0B1 gene function, as proven by the lower NR0B1 protein levels in cells with NR0B1 mutation (measured by western blot) compared with wild type cells [29]. The vast majority of missense mutations are reported to occur in the putative carboxyl terminal LBD, specifically within two clusters between codons $262-300$ and $361-385$, with a scattering of further missense mutations immediately adjacent to the carboxyl terminus [5]. Both the mutations we describe fall around the first of these "hotspots".

Genetic analyses in our patients were performed by bi-directional sequencing of exons 1 and 2 of NROB1. A limitation to our case reports is that the results of some endocrine investigations are not available for our patients, including the values of the ACTH and plasma renin activity at the time of diagnosis of primary AI. This is because in both cases, the initial diagnosis of primary AI was made approximately 20 years prior to the genetic confirmation of the mutation in the DAX-1 gene and therefore some historic medical data is no longer available in the patients' hospital records.

Adult presentation of patients with DAX-1 mutations likely reflects partial, rather than complete loss of repressor activity, as demonstrated in transient gene expression studies and from structural predictions [24, 27, 28]. The finding of two unrelated cases within our center, where we follow-up approximately $40-50$ cases of primary AI, suggests presentation of DAX-1 during adulthood may be under-recognized. This hypothesis was investigated in a cohort of 29 male and female patients with adult-onset AI where common causes including autoimmune disease, steroidogenic defects, and metabolic disorders (e.g. adrenoleukodystrophy) had been excluded. Within this cohort no patients were found to have a DAX-1 mutation [6]. However, none of these patients were reported to have concurrent hypogonadism. The current report strongly suggests that the combination of primary AI with $\mathrm{HH}$ at any age should raise the suspicion of DAX-1 gene mutation, and prompt genetic testing. Diagnosing $\mathrm{X}$-linked AHC is clinically important for identifying siblings who could be at risk of life-threatening AI [26], identifying sisters who might have affected sons, and optimising approaches to endocrine replacement and fertility treatment. As the hypogonadism can occur some time after the diagnosis of adrenal insufficiency, awareness of this condition, careful monitoring, and possibly, genetic testing is warranted.

Funding No funding was received for this case study. JCA is a Wellcome Trust Senior Research Fellow in Clinical Science (Grant 098513/Z/12/Z) with support from the National Institute for Health Research Biomedical Research Centre at Great Ormond Street Hospital for Children NHS Foundation Trust and UCL. 


\section{Compliance with Ethical Standards}

Conflict of interest The authors declare that they have no conflicts of interest.

Ethical Approval This article does not contain any studies with human participants or animals performed by any of the authors. The genetic analysis in both cases was done as part of clinical practice.

Informed Consent Informed consent was obtained from all individual participants included in this case study.

Open Access This article is distributed under the terms of the Creative Commons Attribution 4.0 International License (http:// creativecommons.org/licenses/by/4.0/), which permits unrestricted use, distribution, and reproduction in any medium, provided you give appropriate credit to the original author(s) and the source, provide a link to the Creative Commons license, and indicate if changes were made.

\section{References}

1. Muscatelli F, Strom TM, Walker AP, Zanaria E, Récan D, Meindl A, Bardoni B, Guioli S, Zehetner G, Rabl W, Schwarz HP, Kaplan JC, Camerino G, Meitinger T, Monaco AP (1994) Mutations in the DAX-1 gene give rise to both X-linked adrenal hypoplasia congenita and hypogonadotropic hypogonadism. Nature 372:672-676

2. Zanaria E, Muscatelli F, Bardoni B, Strom TM, Guioli S, Guo W, Lalli E, Moser C, Walker AP, McCabe ER, Meitinger T, Monaco AP, Sassone-Corsi P, Camerino G (1994) An unusual member of the nuclear hormone receptor superfamily responsible for X-linked adrenal hypoplasia congenita. Nature 372:635-641

3. Reutens AT, Achermann JC, Ito M, Ito M, Gu WX, Habiby RL, Donohoue PA, Pang S, Hindmarsh PC, Jameson JL (1999) Clinical and functional effects of mutations in the DAX-1 gene in patients with adrenal hypoplasia congenita. J Clin Endocrinol Metab 84:504-511

4. Landau Z, Hanukoglu A, Sack J, Goldstein N, Weintrob N, Eliakim A, Gillis D, Sagi M, Shomrat R, Kosinovsky EB, Anikster Y (2010) Clinical and genetic heterogeneity of congenital adrenal hypoplasia due to NR0B1 gene mutations. Clin Endocrinol 72:448-454

5. Suntharalingham JP, Buonocore F, Duncan AJ, Achermann JC (2015) DAX-1 (NR0B1) and steroidogenic factor-1 (SF1, NR5A1) in human disease. Best Pract Res Clin Endocrinol Metab 29:607-619

6. Lin L, Gu WX, Ozisik G, To WS, Owen CJ, Jameson JL, Achermann JC (2006) Analysis of DAX1 (NR0B1) and steroidogenic factor-1 (NR5A1) in children and adults with primary adrenal failure: ten years' experience. J Clin Endocrinol Metab 91:3048-3054

7. Sali A, Blundell TL (1993) Comparative protein modelling by satisfaction of spatial restraints. J Mol Biol 234:779-815

8. Sablin EP, Woods A, Krylova IN, Hwang P, Ingraham HA, Fletterick RJ (2008) The structure of corepressor Dax-1 bound to its target nuclear receptor LRH-1. Proc Natl Acad Sci USA 105:18390-18395

9. Brooks BR, Brooks CL, Mackerell AD, Nilsson L, Petrella RJ, Roux B, Won Y, Archontis G, Bartels C, Boresch S, Caflisch A, Caves L, Cui Q, Dinner AR, Feig M, Fischer S, Gao J, Hodoscek M, Im W, Kuczera K, Lazaridis T, Ma J, Ovchinnikov V, Paci E,
Pastor RW, Post CB, Pu JZ, Schaefer M, Tidor B, Venable RM, Woodcock HL, Wu X, Yang W, York DM, Karplus M (2009) CHARMM: the biomolecular simulation program. J Comput Chem 30:1545-1614

10. Ito M, Yu R, Jameson JL (1997) DAX-1 inhibits SF-1-mediated transactivation via a carboxy-terminal domain that is deleted in adrenal hypoplasia congenita. Mol Cell Biol 17:1476-1483

11. Mantovani G, De Menis E, Borretta G, Radetti G, Bondioni S, Spada A, Persani L, Beck-Peccoz P (2006) DAX1 and X-linked adrenal hypoplasia congenita: clinical and molecular analysis in five patients. Eur J Endocrinol 154:685-689

12. Yu RN, Ito M, Saunders TL, Camper SA, Jameson JL (1998) Role of Ahch in gonadal development and gametogenesis. Nat Genet 20:353-357

13. Seminara SB, Achermann JC, Genel M, Jameson JL, Crowley WF Jr (1999) X-linked adrenal hypoplasia congenita: a mutation in DAX1 expands the phenotypic spectrum in males and females. J Clin Endocrinol Metab 84:4501-4509

14. Frapsauce C, Ravel C, Legendre M, Sibony M, Mandelbaum J, Donadille B, Achermann JC, Siffroi JP, Christin-Maitre S (2011) Birth after TESE-ICSI in a man with hypogonadotropic hypogonadism and congenital adrenal hypoplasia linked to a DAX-1 (NR0B1) mutation. Hum Reprod 26:724-728

15. Merke DP, Tajima T, Baron J, Cutler GB Jr (1999) Hypogonadotropic hypogonadism in a female caused by an X-linked recessive mutation in the DAX1 gene. N Engl J Med 340:1248-1252

16. Barbaro M, Oscarson M, Schoumans J, Staaf J, Ivarsson SA, Wedell A (2007) Isolated 46,XY gonadal dysgenesis in two sisters caused by a Xp21.2 interstitial duplication containing the DAX1 gene. J Clin Endocrinol Metab 92:3305-3313

17. Shaikh MG, Boyes L, Kingston H, Collins R, Besley GT, Padmakumar B, Ismayl O, Hughes I, Hall CM, Hellerud C, Achermann JC, Clayton PE (2008) Skewed X inactivation is associated with phenotype in a female with adrenal hypoplasia congenita. $\mathrm{J}$ Med Genet 45:e1

18. Phelan JK, McCabe ER (2001) Mutations in NR0B1 (DAX1) and NR5A1 (SF1) responsible for adrenal hypoplasia congenita. Hum Mutat 18:472-487

19. Nakae J, Tajima T, Kusuda S, Kohda N, Okabe T, Shinohara N, Kato M, Murashita M, Mukai T, Imanaka K, Fujieda K (1996) Truncation at the C-terminus of the DAX-1 protein impairs its biological actions in patients with X-linked adrenal hypoplasia congenita. J Clin Endocrinol Metab 81:3680-3685

20. Achermann JC, Ito M, Silverman BL, Habiby RL, Pang S, Rosler A, Jameson JL (2001) Missense mutations cluster within the carboxyl-terminal region of DAX-1 and impair transcriptional repression. J Clin Endocrinol Metab 86:3171-3175

21. Peter M, Viemann M, Partsch CJ, Sippell WG (1998) Congenital adrenal hypoplasia: clinical spectrum, experience with hormonal diagnosis, and report on new point mutations of the DAX-1 gene. J Clin Endocrinol Metab 83:2666-2674

22. Sekiguchi Y, Hara Y, Matsuoka H, Hayashi Y, Katsumata N, Hirata Y (2007) Sibling cases of Addison's disease caused by DAX-1 gene mutations. Intern Med 46:35-39

23. Achermann JC, Silverman BL, Habiby RL, Jameson JL (2000) Presymptomatic diagnosis of X-linked adrenal hypoplasia congenita by analysis of DAX1. J Pediatr 137:878-881

24. Ozisik G, Mantovani G, Achermann JC, Persani L, Spada A, Weiss J, Beck-Peccoz P, Jameson JL (2003) An alternate translation initiation site circumvents an amino-terminal DAX1 nonsense mutation leading to a mild form of X-linked adrenal hypoplasia congenita. J Clin Endocrinol Metab 88:417-423

25. Raffin-Sanson ML, Oudet B, Salenave S, Brailly-Tabard S, Pehuet M, Christin-Maitre S, Morel Y, Young J (2013) A man with a DAX1/NR0B1 mutation, normal puberty, and an intact hypothalamic-pituitary-gonadal axis but deteriorating 
oligospermia during long-term follow-up. Eur $\mathrm{J}$ Endocrinol 168:K45-K50

26. Guclu M, Lin L, Erturk E, Achermann JC, Cangul H (2010) Puberty, stress, and sudden death. Lancet 376:1512

27. Mantovani G, Ozisik G, Achermann JC, Romoli R, Borretta G, Persani L, Spada A, Jameson JL, Beck-Peccoz P (2002) Hypogonadotropic hypogonadism as a presenting feature of late-onset $\mathrm{X}$-linked adrenal hypoplasia congenita. J Clin Endocrinol Metab 87:44-48
28. Tabarin A, Achermann JC, Recan D, Bex V, Bertagna X, Christin-Maitre S, Ito M, Jameson JL, Bouchard P (2000) A novel mutation in DAX1 causes delayed-onset adrenal insufficiency and incomplete hypogonadotropic hypogonadism. J Clin Invest 105:321-328

29. Oh CM, Chun S, Lee JE, Lee JS, Park S, Gee HY, Kim SW (2017) A novel missense mutation in NR0B1 causes delayedonset primary adrenal insufficiency in adults. Clin Genet. doi:10.1111/cge.12966 